\title{
Machado-Joseph Disease Enhances Genetic Fitness: A Comparison Between Affected and Unaffected Women and Between MJD and the General Population
}

\author{
P. R. Prestes ${ }^{1}$, M. L. Saraiva-Pereira ${ }^{1,2,4}$, I. Silveira ${ }^{5}$, J. Sequeiros ${ }^{5}$ and L. B. Jardim ${ }^{1,3,4, *}$ \\ Departments of ${ }^{1}$ Genetics and Molecular Biology, of ${ }^{2}$ Biochemistry, and of ${ }^{3}$ Internal Medicine, Universidade Federal do Rio Grande do \\ Sul, Brazil \\ ${ }^{4}$ Medical Genetics Service, Hospital de Clínicas de Porto Alegre, Brazil \\ ${ }^{5}$ Instituto de Biologia Molecular e Celular, Universidade do Porto, Portugal
}

\section{Summary}

Background: Machado-Joseph disease (MJD SCA3), a spinocerebellar ataxia related to expansion of a CAG tract, has already been related to anticipation and meiotic drift. However, fitness of MJD carriers has been little studied. Objective: To analyze genetic fitness of MJD patients, comparing them to their unaffected relatives and to the general population (GP) of origin. Subjects and methods: 182 informants, belonging to 82 MJD families, agreed to participate in the study. Informants supplied data about 828 MJD patients. Number of children (NC), gender, age, school attainment, menarche and menopause were compared between general and emeritus (older than 45 years of age or deceased) groups. Results: Mean NC of the GP and of MJD patients were respectively 1.90 and 2.93 $2.3(\mathrm{p}=0.0037)$. Comparisons within families also showed differences: the mean NC of unaffected and affected emeritus MJD women were, respectively, 2.68 and 3.89 ( $\mathrm{p}=0.0037$ ). Affected MJD women had earlier mean ages at the delivery of their first child and menopause ( $\mathrm{p}<0.011$ and 0.07 , respectively). Among affected women those who did not have children had larger CAG tracts than those who had children $(\mathrm{p}<0.05)$. Conclusion: MJD enhances the fitness of its carriers, and this phenomenon seems to have a biological basis.

Keywords: genetic fitness, fertility, Machado-Joseph disease, polyglutamine diseases, spinocerebellar ataxias

\section{Introduction}

Machado-Joseph disease (MJD or SCA3), a spinocerebellar ataxia of adulthood, is related to expansion of a CAG tract at the MJD1 locus at $14 \mathrm{q} 32.1$ above the threshold of about 54-86 repeats (Takiyama et al. 1993, Kawaguchi et al. 1994; Bauer et al. 2005). The expanded allele is dominant, and there is an important correlation between repeat amplification and symptom severity in affected individuals. Since the disease usually starts after reproductive age most affected individuals have children before knowing their genetic status. Predictive testing is available, but it is asked for by a minority of people at risk (Rolim et al. 2006).

\footnotetext{
* Corresponding author: Laura B. Jardim, Medical Genetics Service, Hospital de Clínicas de Porto Alegre, Rua Ramiro Barcelos 2350, 90.035-903 Porto Alegre, Brazil. Tel: + 55512101 8011; Fax: + 55512101 8010. E-mail: ljardim@hcpa.ufrgs.br
}

A worldwide prevalence estimate of spinocerebellar ataxias (SCA) in general is about 3/100,000; MJD would account for $21 \%$ of these cases (Schöls et al. 2004). MJD is found in $92 \%$ of South Brazilian SCA families, and has an estimated prevalence of 1.8:100,000 inhabitants (Jardim et al. 2001).

Among selective forces influencing the prevalence of $\mathrm{MJD}$, at least three have merited some investigation: anticipation, meiotic drift, and genetic fitness. Anticipation, which is explained by a tendency for repeats to expand during vertical transmission (particularly in paternal transmission) and by age of onset being inversely correlated to the repeat length, is a well-known phenomenon in MJD (Maciel et al. 1995). Anticipation is expected to produce strong negative selection of the expanded allele.

Clinical observations and single sperm analysis of CAG repeats have shown the existence of a segregation distortion favouring the expanded allele (Ikeuchi et al. 1996; Iughetti et al. 1998; Takiyama et al. 1995). The advantage assigned 
to gametes may be acting in fertilization or in a post-zygotic phase (Leeflang et al. 1996), and would result in a positive selection of the expanded allele.

To our knowledge fitness has rarely been studied in MJD. Investigations have been limited to comparisons within families (Silva et al. 1997). The objective of the present study was to analyze the genetic fitness of MJD patients, and to compare these results to those from the general population of origin.

\section{Material and Methods}

This study was approved by the local ethics committee. After consent an interview was performed with patients and their relatives aged 18 or over whose families had a molecular diagnosis of $\mathrm{MJD}$, as well as follow-up visits to our Institution. All cases belonged to MJD families that had registered at our Institution. All informants were interviewed in person, and each provided data on his/her relatives, following a structured questionnaire about each family member. Only individuals with entirely known reproductive history were included. Data was double-checked by a second (or a third, and so on) informant from the same family: only concordant information was included. Individuals born before 1903 were not included in the study. Rio Grande do Sul, the southernmost state of Brazil, was the geographical origin of all families; all studied cases were carriers of the A-C-A haplotype (Bressel, 2003).

Results were also compared to those found by the 2000 Brazilian Demographic Census (IBGE, 2000). In order to avoid data duplication the census only registered the number of children of each woman. Therefore, only the results of female MJD patients were compared to data on the general population. All data was corrected to the year 2000 .

Among MJD family members associations were sought between the number of children (NC) and the following individual characteristics: age, sex, genetic status (symptomatic or asymptomatic) of individuals older than 45, school attainment, age at onset (if symptomatic), CAGn (if applied), age at menarche, and at menopause (if applied). Ages at delivery of the first and last child were also studied.

Three main stratifications were made: (a) the number of children (NC) of symptomatic ("affected") versus asymptomatic ("unaffected") relatives over 45 years old; (b) the NC of MJD women versus the general population of women in Rio Grande do Sul, and (c) the NC of MJD women versus women in the general population over 45 years old. This ceiling age was chosen for two reasons: first, women over 45 years of age have usually already finished their reproductive period and are considered emeritus; therefore, their fitness can be reliably estimated; and second, asymptomatic individuals over 45 years have such a low risk of being carriers of the MJD1 mutation that they can be approximated as non-carriers. Most of the present data relied on reported phenotypes and not on genotypes. For this reason the strategy of classifying individuals as affected or unaffected by their phenotype at age 45 or over was chosen, even if the so-called unaffected group could have included some carriers (with a later age of on- set, unknown to the related informants, or who died after 45 but before the symptomatic age).

Fitness was calculated in two ways, as follows: considering the total number of children (NC) born to women either older than 45 or deceased before that age (from normal causes), and considering the total number of children of all individuals. Since only recent generations were included in the analysis, biases due to losses related to prereproductive mortality were considered negligible, and the offspring also included young children. The mean NC obtained for the general population was equalled to a fitness value of 1 . The fitness of MJD patients was expressed as a proportion relative to this standard.

Means between groups were analyzed using Student's $t$ or Mann-Whitney's U test according to the distribution of variables and to data acquisition. Other comparisons were made using the ANOVA and Kruskal-Wallis $\mathrm{H}$ tests. In order to test correlations between measures, Pearson's coefficient was employed for continuous variables and Spearman's rank test for ordinal or not normally distributed variables. Bonferroni correction was performed due to multiple testing. All tests were two-tailed; $p$ values less than 0.05 were considered statistically significant. Statistical analyses were performed using SPSS 14.0 for Windows.

\section{Results}

One hundred and five MJD families were identified in Rio Grande do Sul, Brazil and 82 families were recruited; 182 informants agreed to participate in this study. Data from 828 (415 affected) individuals belonging to those 82 MJD families were included. Table 1 shows the general characteristics of the study sample.

Twenty-three of the 105 families were not included: one family did not agree to participate in the study, and another 22 were not traced by correspondence or telephone calls after repeated attempts (true losses). A general comparison of the previously known pedigrees of families included and lost did not reveal rough differences.

\section{Estimated Prevalence of MJD in Southern Brazil}

Data from 272 MJD patients of 82 families alive in the 2000 census was available. Considering the same proportion of cases to be alive in the 105 families diagnosed as having MJD in the state, the prevalence of MJD patients in that year was estimated to be 350 . This figure corresponds to a prevalence of 3.5/100,000 inhabitants in the state of Rio Grande do Sul.

\section{Differential Fitness of Affected Individuals in the MJD Cohort Versus in the General Population}

In 2000, the female population in Rio Grande do Sul totaled 4,338,076 women. The mean NC of the female 
Table 1 Characteristics of the studied sample

\begin{tabular}{|c|c|c|c|c|c|}
\hline & & Symptomatic & Asymptomatic & Total & $\mathrm{P}$ \\
\hline Families & & & & 82 & \\
\hline \multirow[t]{2}{*}{ Individuals } & & 415 & 413 & 828 & \\
\hline & $\begin{array}{l}\text { Mean age } \pm d p \\
\text { (range) }\end{array}$ & $47,85 \pm 17,642$ & $33,67 \pm 14$ & $40,74 \pm 17,472$ & 0.0009 \\
\hline Deceased & & 143 & 15 & 158 & \\
\hline \multicolumn{6}{|l|}{ of age } \\
\hline \multirow[t]{2}{*}{ Women } & & 222 & 221 & 443 & \\
\hline & Mean age & $46,08 \pm 16,948$ & $33,02 \pm 14,034$ & $39,55 \pm 16,860$ & ns \\
\hline \multirow[t]{2}{*}{ Men } & & 193 & 192 & 385 & \\
\hline & Mean age & $49,91 \pm 18,246$ & $34,41 \pm 14,229$ & $42,12 \pm 18,079$ & \\
\hline \multirow[t]{2}{*}{$\begin{array}{l}\text { Women over } 45 \text { years } \\
\text { of age }\end{array}$} & & 112 & 47 & 159 & 0.18 \\
\hline & Mean age & $59,57 \pm 11,768$ & $53,45 \pm 8,680$ & $57.7 \pm 11.2$ & \\
\hline \multirow[t]{2}{*}{ Men over 45 years of age } & & 115 & 42 & 157 & \\
\hline & Mean age & $61,26 \pm 13,414$ & $54,79 \pm 10,669$ & $59.5 \pm 13$ & \\
\hline CAGn Mode(n; range) & & 73 (78 patients; 69-83) & & & \\
\hline \multirow[t]{3}{*}{$\begin{array}{l}\text { Mean } \pm \text { SD age at } \\
\text { onset of symptoms } \\
\text { (n; range) }\end{array}$} & & $36,38 \pm 11,294$ & & & \\
\hline & Women & $35.3 \pm 10$ & & & ns \\
\hline & Men & $37.7 \pm 11$ & & & \\
\hline $\begin{array}{l}\text { Median age at } \\
\text { death (n; range) }\end{array}$ & & 58 (143 individuals; $20-85$ ) & 52 (15 individuals; 18-87) & & 0.3 \\
\hline
\end{tabular}

population and the mean NC of MJD patients were 1.90 and $2.93 \pm 2.3$, respectively, and this difference was significant ( $p=0.0037)$. If the population fitness equals 1 , then the MJD fitness is 1.54 .

These figures can be stratified into a subgroup of women who had completed their reproductive life - women called emeritus - and a subgroup of women still in their reproductive age. These results are shown in Table 2.

Checking the diverse distribution of social classes was mandatory, because one supposes that low social income is related to an increased NC. It is known that low social income rates are the most prevalent strata in the Brazilian population (IBGE, 2000). Since a significant part of the MJD sample lacked data about income rates, school attainment was used to evaluate social class distribution. No statistical differences were found between the MJD sample and the general population.

\section{Differential Fitness of Affected Versus Unaffected Individuals in the MJD Cohort}

Affected MJD individuals had a significantly higher NC than unaffected relatives. The most reliable comparison was between affected and unaffected MJD women over 45 years of age, or already deceased, because their offspring could be reliably estimated. Results are shown in Table 3. This phenomenon appeared both in the women's and the men's offspring. The NC of MJD did not vary between genders. Therefore, no gender effect was acting on fitness.

In order to test if an early perception of disease could influence fertility decisions, emeritus affected MJD women were also stratified according to their age at the onset of symptoms. Results confirmed that emeritus affected women had more children than unaffected women, even when the disease started later than the age of 30 years (Table 3).

Early MJD individuals without offspring would be absolutely lost at the end of the observation in a cohort starting, for instance, two hundred years ago. On the contrary, the effect on progeny of individuals with no children could be measured in a contemporary cohort. Table 4 compares only contemporary women who had completed their fertile period, i.e., those born between 1936 and 1955 (between 45 and 64 years of age in 2000, or deceased). Larger "family sizes" were more frequent in the affected than in the groups of unaffected women $(p<0.029$, Mann-Whitney U test) (Table 4). Emeritus MJD women with no offspring were also less frequent than their unaffected female relatives without offspring. 
Table 2 Fitness of MJD affected women versus the general female population

\begin{tabular}{|c|c|c|c|c|c|}
\hline & \multicolumn{2}{|c|}{ General female population } & \multicolumn{2}{|c|}{ MJD affected women } & \multirow[t]{2}{*}{$\mathrm{P}$} \\
\hline & $\begin{array}{l}\text { Number of } \\
\text { women } \\
(\%)\end{array}$ & $\begin{array}{l}\text { Mean Number } \\
\text { of children } \\
\text { (range) }\end{array}$ & $\begin{array}{l}\text { Number of } \\
\text { women }\end{array}$ & $\begin{array}{l}\text { Mean } \pm \text { sd Number } \\
\text { of children } \\
\text { (range) }\end{array}$ & \\
\hline All ages & $4,338,076$ & 1.90 & 222 & $\begin{array}{l}2.93 \pm 2.3 \\
(0-13)\end{array}$ & $\mathrm{p}<0.0037^{* *}$ \\
\hline Fitness & & 1 & & 1.54 & \\
\hline $\begin{array}{l}\text { Emeritus (Over } \\
45 \text { years) }{ }^{*}\end{array}$ & $1,411,604$ & 3.52 & 112 & $\begin{array}{l}3.89 \pm 2.52 \\
(0-13)\end{array}$ & $\mathrm{p}=0.1^{* *}$ \\
\hline Fitness & & 1 & & 1.1 & \\
\hline $\begin{array}{l}\text { Between } 10 \text { and } \\
44 \text { years }\end{array}$ & $2,926,425$ & 1.12 & 110 & $\begin{array}{l}1.95 \\
(0-9)\end{array}$ & $\mathrm{p}<0.0037^{* *}$ \\
\hline Fitness & & 1 & & 1.74 & \\
\hline $\begin{array}{l}\text { Women who } \\
\text { did not have } \\
\text { children }\end{array}$ & $\begin{array}{l}1,482,010 / 4,338,076 \\
(34.16 \%)\end{array}$ & 0 & $\begin{array}{l}28 / 222 \\
(12.6 \%)\end{array}$ & 0 & $\mathbf{p}<0.0037^{* * *}$ \\
\hline $\begin{array}{l}\text { Contemporary, } \\
\text { emeritus women } \\
\text { (born between } 1936 \\
\text { and 1955) who } \\
\text { did not have children }\end{array}$ & $\begin{array}{l}100,748 / 979,688 \\
(10.28 \%)\end{array}$ & 0 & $\begin{array}{l}6 / 75 \\
(8.0 \%)\end{array}$ & 0 & $\mathrm{p}>0.2^{* * *}$ \\
\hline
\end{tabular}

* The subgroup of emeritus MJD women also included dead women, since in both cases (alive and over 45 or dead) their offspring were completely known.

${ }^{* *} \mathrm{~T}$ test.

*** Chi-square.

\begin{tabular}{|c|c|c|c|c|}
\hline & Affected & Unaffected & $\mathrm{p}$ & Total \\
\hline Number of women & 112 & 47 & & 159 \\
\hline $\begin{array}{l}\text { Mean number of } \\
\text { children } \pm \text { sd }\end{array}$ & $3.89 \pm 2.5$ & $2.68 \pm 2$ & $0.0037^{*}$ & \\
\hline Fitness & $\begin{array}{l}1.45 \\
\text { Symptoms } \\
\text { starting } \\
\text { after } 30 \text { yo }\end{array}$ & $\begin{array}{l}1 \\
\text { Unaffected }\end{array}$ & & \\
\hline Number of women & 93 & 47 & & 140 \\
\hline $\begin{array}{l}\text { Mean number of } \\
\text { children } \pm \text { sd }\end{array}$ & $4.03 \pm 2.5$ & $2.68 \pm 2$ & $0.0037^{*}$ & \\
\hline
\end{tabular}

\section{Reproductive Interval of MJD Affected Women Versus Unaffected Women}

Mean age at delivery of the first child was lower in affected women when compared to unaffected MJD women $(p=0.011)$, and there seemed to be a trend for longer reproductive intervals in MJD women, as shown in Table 5. Interestingly enough, MJD women had their menarche at the same age as the general population but had their menopause at an earlier age $(p=0.01)$.

\section{MJD Severity Versus Fertility}

Although not the main objective of this study, two parameters of severity were obtained from the present sample: age at onset of all affected individuals and CAGn, when available.

There was a direct although weak correlation between age at onset of symptoms and NC $(r=0.322, p<$ 0.0011 , Spearman correlation test) (Figure 1). Similarly, in 78 MJD patients CAGn was inversely correlated to NC 
Table 4 Number of children of emeritus contemporary MJD women born between 1936 and 1955

\begin{tabular}{|c|c|c|c|c|c|c|c|c|c|c|c|c|c|}
\hline & \multicolumn{13}{|c|}{ Number of children (family size) } \\
\hline & & & Total & & $\mathrm{p}$ & & & & & & & & \\
\hline & Zero & 1 & 2 & 3 & 4 & 5 & 6 & 7 & 8 & 9 & 10 & 11 & 12 \\
\hline \multirow[t]{3}{*}{ Unaffected women } & 6 & 2 & 13 & 11 & 4 & 2 & 0 & 2 & 0 & 0 & 1 & 0 & 0 \\
\hline & $(14.6 \%)$ & & $\begin{array}{l}41 \\
(63.4 \%)\end{array}$ & & & $(14.6 \%)$ & & & & & $(7.3 \%)$ & & \\
\hline & & & & & $0.029^{*}$ & & & & & & & & \\
\hline \multirow[t]{2}{*}{ Affected women } & 6 & 1 & $\begin{array}{l}21 \\
75\end{array}$ & 15 & 8 & 13 & 2 & 6 & 1 & 0 & 1 & 0 & 1 \\
\hline & $(8 \%)$ & & $(49.3 \%)$ & & & $(30.6 \%)$ & & & & & $(12 \%)$ & & \\
\hline Total & 12 & 3 & $\begin{array}{l}34 \\
116\end{array}$ & 26 & 12 & 15 & 2 & 8 & 1 & 0 & 2 & 0 & 1 \\
\hline
\end{tabular}

*Mann-Whitney U test.

Table 5 Reproductive characteristics of MJD emeritus, affected and unaffected women, and the general population

\begin{tabular}{|c|c|c|c|c|}
\hline & Affected & $\begin{array}{l}\text { Unaffected at } 45 \text { years or more } \\
\text { average } \pm \mathrm{sd} \\
\text { (n; range) }\end{array}$ & General Population & $\mathrm{P}$ \\
\hline Age at delivery of first offspring & $\begin{array}{l}21.8 \pm 4.6 \\
(102 ; 14-42 \text { years })\end{array}$ & $\begin{array}{l}24.2 \pm 3.7 \\
(36 ; 16-32 \text { years })\end{array}$ & & $0.011^{*}$ \\
\hline Age at delivery of last offspring & $\begin{array}{l}31.6 \pm 6.1 \\
(102 ; 16-46 \text { years })\end{array}$ & $\begin{array}{l}32.2 \pm 5.6 \\
(36 ; 22-43 \text { years })\end{array}$ & & $\mathrm{ns}^{*}$ \\
\hline Reproductive interval & $\begin{array}{l}9.75 \pm 6.0 \\
(102 ; 0-29 \text { years })\end{array}$ & $\begin{array}{l}8.0 \pm 6.6 \\
(36 ; 0-27 \text { years })\end{array}$ & & $0.07^{*}$ \\
\hline Age at menarche $\mathrm{A}^{\#}$ & $\begin{array}{l}12.9 \pm 1.8 \\
(30 ; 10-17 \text { years })\end{array}$ & $\begin{array}{l}12.1 \pm 1.2 \\
(32 ; 9-15 \text { years })\end{array}$ & $12.9^{* * *}$ & $1.0^{* *}$ \\
\hline Age at menopause ${ }^{\#}$ & $\begin{array}{l}46.87 \pm 5.1 \\
(15 ; 38-56 \text { years })\end{array}$ & 55 (1 case) & $51.2^{* * * *}$ & $0.01^{* *}$ \\
\hline
\end{tabular}

*Although mean \pm SD are presented, Mann-Whitney $U$ test was performed due to the distribution of variables.

** Student's t test.

*** Thomas et al. 2001.

**** Pedro et al. 2003.

\#limited data: information here were only obtained when the informant was, at the same time, the individual under study.

$(\mathrm{r}=-0.281, \mathrm{p}<0.0011$, Spearman). The possible effect of CAGn on fertility is also shown in Figure 2; that is, MJD women who did not have children had larger CAGn (76 CAGs) than MJD women who had children (74 CAGs) $(p<0.05$, Mann-Whitney U test).

\section{Discussion}

Genetic fitness was analyzed in MJD families from a definite geographical area who had a homogeneous origin; all these families were possible carriers of the A-C-A haplotype. In this set of data MJD patients born after 1903 had an increased genetic fitness, both when compared to their asymptomatic relatives and when compared to the general population.
In all comparisons with the general population we used data acquired through the Brazilian Census of 2000. Since distribution of NC was not exactly normal, the ideal statistics would be the Mann-Whitney test. For that test we would need to have acquired all individual data on the entire population (of around 4 million people), which was unfeasible. As neither the standard deviation nor standard error of the distribution of number of children in the population were available (not even in The Brazilian Institute of Geography and Statistics), we finally chose to perform $\mathrm{t}$ test statistics. Although the lack of variation among controls could produce false significances, the $t$ test, using the standard deviation of the cases, was the only remaining statistic suitable for the present comparisons. However, we appreciated that, with such huge figures, the probability of obtaining false significances was low. 


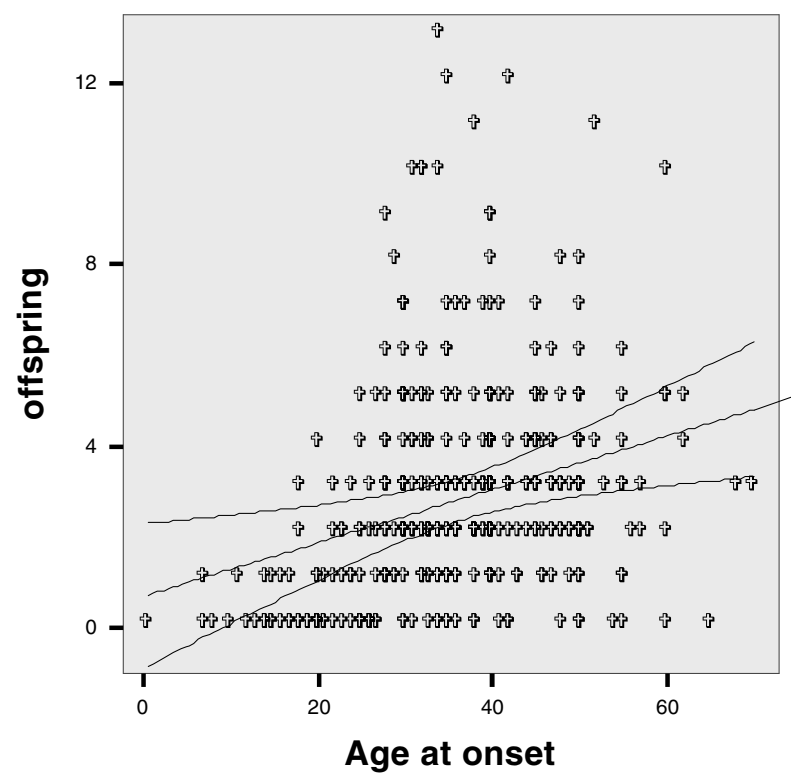

Figure 1 Correlation between age at onset and number of children (offspring) of MJD women.

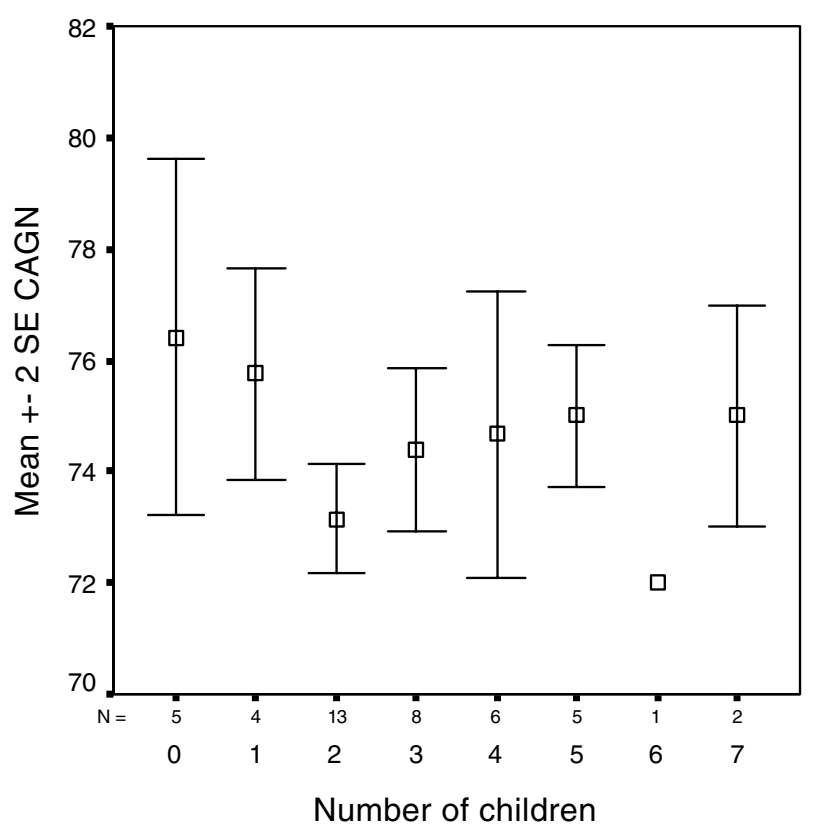

Figure 2 CAGn of MJD affected women according to their number of children.

Intrafamilial comparisons were very interesting. MJD carriers older than 45 had significantly more offspring than their asymptomatic (or unaffected) relatives: 3.89 versus 2.68 children, on average. We wish to highlight the fact that this control group was actually a combination of carriers of abnormal and (the majority) normal genotypes. And, in spite of this possible blurring, differences persisted. However, the comparison between the MJD sample and the general population revealed a pitfall. Although emeritus MJD women (older than 45 or deceased) had on average more offspring than the general population of emeritus women (3.89 versus 3.52 children), this difference was not significant. One possible explanation for this finding was the sample size (112 MJD individuals). Perhaps significance could be obtained with a larger sample; this remains to be demonstrated.

The NC of MJD women younger than 45 was higher than that of the general female population of the same age. Enhanced fertility in the early years of adulthood that disappears in later years is a possibility, and would be in accord with the suggestive finding of an earlier menopause in MJD women. Another explanation could be that MJD women living from 1980 onwards, with some biological trend to be fertile, were not so prone to the demographic transition, i.e., the progressive reduction of the mean number of children that follows a previous reduction in mortality in populations under industrial development (Montgomery, 2006).

MJD individuals born a very long time ago who had no offspring would be easily lost from a long duration cohort. In contrast, measuring fertility in a recent contemporary cohort enabled us to include information on individuals with no offspring. We analyzed the family size of contemporary MJD affected versus unaffected women, and compared the number of women with no children in both groups. First, women with no children were more common in the unaffected group than in the affected group. Therefore, normal CAG tracts were probably lost in the genetic pool of these families more often than expanded CAGs. On the other hand, affected women with no children had larger CAGn than those who had offspring: these longer expansions will actually be lost from the following generations.

The population genetics of MJD has revealed some phenomena that are in accord with enhanced fitness of the mutated allele. The worldwide association of MJD to a limited set of haplotypes - haplotype A-C-A being shared by $71 \%$ of $270 \mathrm{MJD}$ families from 24 different origins (Martins et al. in press) - strongly supports the maintenance of this set of expanded alleles in spite of selection. Under the assumption of a mutation/selection equilibrium, the expanded alleles lost at each generation in severe (early onset) MJD cases with no offspring can be replaced by new mutations. However, new mutations would introduce variation in intra- and extragenic markers. This is not the case for MJD expansions. Only five extended haplotypes have been described, confirming that the disease frequency is mainly explained by two mutational events occurring in the A-C-A and G-G-C lineages (Gaspar et al. 2001; Martins et al. 2007). The only other way to explain this haplotype homogeneity would be linkage between these 
haplotypes, and factors predisposing to mutation. In any case, new mutations have never been described in this disease.

Two findings suggest selection against the larger expansions. First, the fact that the earlier the disease starts the smaller the number of offspring is (Figure 1); second, the association between no offspring and larger CAGn (Figure 2). Carriers of larger expansions are expected to have few children, if any. These results are in agreement with the model proposed by Frontali et al. (1996). Under this model, most of the alleles with the largest expansions would be lost at each generation, while the pool of the low/medium expansions would be maintained by the increased fitness of their carriers.

One can only speculate about causes for higher fitness in carriers of MJD expansions. As Frontali et al. (1996) have pointed out, these causes "include possible effects of CAG expansions on reproductive physiology or on sexual drive and behavior". For instance, CAG expansion could have an effect on reproduction: this could explain why carriers were younger at the delivery of their first child and, apparently, have a trend towards an earlier menopause than the general population.

Any change in reproduction associated with CAG expansion seems to be independent of psychological mechanisms. Both asymptomatic and symptomatic women over 45 , whose disease started after their thirties, tended to have their offspring on average before the onset of the disease (from 21 to 31.6 years in the case of carriers whose disease started after 30; and from 24 to 32 years in the case of asymptomatic women over 45 years of age). Both groups had the majority of their offspring when living with the same uncertainty about their future; in spite of this, women who became symptomatic had significantly more children than asymptomatic women.

Evidences in favour of differential fitness have also been found in Huntington disease (HD), SCA1, and allele 4 of the APOE locus (Harper, 1991; Frontali et al. 1996; Charlesworth, 1996). In all these cases mutations lead to neurodegenerative phenotypes appearing after the reproductive age that act like a "neurological senescence". Of course, these mutations are "individually and collectively exceedingly rare and best regarded as leading to private modulations of the senescent phenotype" (Martin, 2001). Notwithstanding, the higher fitness found in these diseases tempt us to see them as possible examples of antagonistic pleiotropy (Williams, 1957). In this speculative scenario a CAG expansion, common to HD, SCA1 and MJD, could anticipate and enhance, to some extent, fertility and fitness, and later be associated with earlier ovarian failure, perhaps mimicking the already known apoptosis that affects neuronal populations in these diseases.
In conclusion MJD expanded alleles, in some unknown way, enhanced the fitness of the carriers in the present sample, and this phenomenon seems to have a biological basis.

\section{Acknowledgements}

We are grateful to the patients and their relatives who agreed to participate in this project. This study was partially supported by CAPES through a scholarship given to P. R. Prestes, and by FAPERGS. Prof. L. Jardim is supported by CNPq.

\section{References}

Bauer, P.O., Kotliarova, S.E., Matoska, V., Musova, Z., Hedvicakova, P., Boday, A., Tomek, A., Nukina, N. \& Goetz, P. (2005) Fluorescent multiplex PCR-fast method for autosomal dominant spinocerebellar ataxias screening. Genetika 41(6), 830-837.

Bressel, T.A.B. (2003) Intragenic haplotype analysis of MJD1 gene in Machado-Joseph disease patients. Master of Science Dissertation, Universidade Federal do Rio Grande do Sul Edition, Portuguese.

Charlesworth, B. (1994) Evolution in age structured populations $2^{\text {sd }}$ edition. Cambridge Univesity Press, New York.

Frontali, M., Sabbadini, G., Novelletto, A., Jodice, C., Naso, F., Spadaro, M., Giunti, P., Jacopini, A.G., Veneziano, L., Mantuano, E., Malaspina, P., Ulizzi, L., Brice, A., Durr, A. \& Terrenato, L. (1996) Genetic fitness in Huntington's Disease and Spinocerebellar Ataxia 1: a population genetics model for $\mathrm{CAG}$ repeat expansions. Ann Hum Genet 60(Pt 5), 423-35; Sep.

Gaspar, C., Lopes-Cendes, I., Hayes, S., Goto, J., Arvidsson, K., Dias, A., Silveira, I., Maciel, P., Coutinho, P., Lima, M., Zhou, Y.X., Soong, B.W., Watanabe, M., Giunti, P., Stevanin, G., Riess, O., Sasaki, H., Hsieh, M., Nicholson, G.A., Brunt, E., Higgins, J.J., Lauritzen, M., Tranebjaerg, L., Volpini, V., Wood, N., Ranum, L., Tsuji, S., Brice, A., Sequeiros, J. \& Rouleau, G.A. (2001) Ancestral origins of the Machado-Joseph disease mutation: a worldwide haplotype study. Am J Hum Genet 68, 523-528.

Harper, P.S. (1991) Huntington's disease. Saunders, London, pp. 294-298.

IBGE - Instituto Brasileiro de Geografia e Estatística (2000) Demographic Census 2000 -[Marriage and fecundity, results from Brazilian Census 2000], Rio de Janeiro, Portuguese, pp. 1-218.

Ikeuchi, T., Igarashi, S., Takiyama, Y., Onodera, O., Oyake, M., Takano, H., Koide, R., Tanaka, H. \& Tsuji, S. (1996) Nonmendelian transmission in dentatorubral-pallidoluysian atrophy and Machado-Joseph disease: the mutant allele is preferentially transmitted in male meiosis. Am J Hum Genet 58, 730-733.

Iughetti, P., Otto, P.A., Zatz, M. \& e Passos-Bueno, M.R. (1998) Different behavior in the paternally vs maternally inherited mutated allele in Brazilian Machado-Joseph (MJD1) families. Am J Med Genet 77, 246-248.

Jardim, L.B., Silveira, I., Pereira, M.L., Ferro, A., Moreira, M.C., Mendonça, P., Ferreirinha, F., Sequeiros, J. \& Giugliani, R. (2001) A survey on spinocerebellar ataxia in South Brazil - 110 new patients with Machado-Joseph disease, SCA7, SCA8, or unidentified isease causing mutations. Journ Neurol. 248, 870-876.

Kawaguchi, Y., Okamoto, T., Taniwaki, M. et al. (1994) CAG expansions in a novel gene for Machado-Joseph disease at chromosome 14q32.1. Nat Genet 8, 221-8. 
Leeflang, E.P., McPeek, M.S. \& Arnheim, N. (1996) Analysis of meiotic segregation, using single sperm typing: meiotic drive at myotonic dystrophy locus. Am J Hum Genet 896-904.

Maciel, P., Gaspar, C., DeStefano, A.L., Silveira, I., Coutinho, P., Radvany, J., Dawson, D.M., Sudarsky, L., Guimaraes, J., Loureiro, J.E.L, Nezarati, M.M., Corwin, L.I., Lopes-Cendes, I., Rooke, K., Rosenberg, R., MacLeod, P., Farrer, L.A., Sequeiros, J. \& Rouleau, G.A. (1995) Correlation between CAG repeat lenght and clinical features in Machado-Joseph disease. Am J Hum Genet 57, 54-61.

Martin, G.M. (2001) Genetics and Aging. In: Scriver, C.R., Beaudet, A.L., Sly, W.S. \& Valle, D. (eds). The metabolic and molecular basis of inherited disease. McGraw-Hill, New York, pp. 215.

Martins, S., Calafell, F., Gaspar, C., Silveira, I., Wong, V., Hsieh, M., Soong, B.-W., Tranebjaerg, L., Brunt, E., Nicholson, G.A., Tsuji, S., Watanabe, M., Jardim, L., Riess, O., Wood, N., Sasaki, H., Ranum, L., Brice, A., Rouleau, G., Coutinho, P., Amorim, A. \& Sequeiros, J. The worldwide spread mutational event in MachadoJoseph disease has an Asian origin. Arch of Neurol, in press.

Montgomery, K. (2006) "The demographic transition". Web page of University of Wisconsin. http://www.uwmc.uwc.edu/ geography/Demotrans/demtran.htm.

Pedro, A.O., Pinto-Neto, A.M., Paiva, L.H.S.C., Osis, M.J. \& Hardy, E. (2003) Age at natural menopause in Brazilian women: a populational survey. Cad. Saúde Pública 19(1), 17-25. Portuguese.

Rolim, L., Leite, A., Ledo, S., Paneque, M., Sequeiros, J. \& Fleming, M. (2006) Psychological aspects of pre-symptomatic testing for Machado-Joseph disease and familial amyloid polyneuropathy type I. Clin Genet 69(4), 297-305.
Schols, L., Bauer, P., Schmidt, T., Schulte, T. \& Riess, O. (2004) Autosomal dominant cerebellar ataxias: clinical features, genetics, and pathogenesis. Lancet Neurol 3(5), 291-304.

Silva, M.C., Coutinho, P., Pinheiro, C.D. et al. (1997) Hereditary ataxias and spastic paraplegias: methodological aspects of a prevalence study in Portugal. J Clin Epidemiol 50, 1377-1384.

Takiyama, Y., Igarashi, S., Rogaeva, E.A. et al. (1995) Evidence for intergenerational instability in the MJD1 gene and for conserved haplotypes at flanking markers amongst Japanese and Caucasian subjects with Machado-Joseph disease. Hum Molec Genet 4, 11371146.

Takiyama, Y., Nishizawa, M., Tanaka, H., Kawashima, S., Sakamoto, H., Karube, Y., Shimazaki, H., Soutome, M., Edo, K., Ohta, S. et al. (1993) The gene for Machado-Joseph disease maps to human chromosome 14q. Nature Genet 4, 300-4.

The 2000 Brazilian Demographic Census. http://www.ibge.gov.br/ home/estatistica/populacao/default_censo_2000.shtm

Thomas, F., Renaud, F., Benefice, E., de Meeus, T. \& Guegan, J.F. (2001) International variability of ages at menarche and menopause: Patterns and main determinants. Hum Biol 2001 Apr; 73(2), 271-90.

Williams, G.C. (1957) Pleiotropy, natural selection, and the evolution of senescence. Evolution 11, 398.

Received: 14 March 2007

Accepted: 2 June 2007 